\title{
Erratum to: Type 2 diabetes risk allele near CENTD2 is associated with decreased glucose-stimulated insulin release
}

\author{
T. Nielsen - T. Sparsø • N. Grarup • T. Jørgensen - C. Pisinger • D. R. Witte • \\ Diabetes Genetics Replication and Meta-analysis \\ (DIAGRAM) Consortium • T. Hansen • O. Pedersen
}

Published online: 18 February 2011

(C) Springer-Verlag 2011

\section{Erratum to: Diabetologia}

DOI 10.1007/s00125-011-2054-3

Unfortunately the author order was incorrect. The correct author list is as follows:

Nielsen T, Sparsø T, Grarup N, Jørgensen T, Pisinger C, Witte DR, Diabetes Genetics Replication and Meta-analysis (DIAGRAM) Consortium, Hansen T and Pedersen O

The online version of the original article can be found at http://dx.doi. org/10.1007/s00125-011-2054-3.

\footnotetext{
T. Nielsen $(\varangle) \cdot$ T. Spars $\varnothing \cdot$ N. Grarup $\cdot$ O. Pedersen

Marie Krogh Center for Metabolic Research, Section of Metabolic Genetics, Faculty of Health Sciences, University of Copenhagen, Universitetsparken 1,

2100 Copenhagen, Denmark

e-mail: trine.nielsen@sund.ku.dk

T. Nielsen $\cdot$ T. Spars $\varnothing \cdot$ N. Grarup $\cdot$ T. Hansen $\cdot$ O. Pedersen

Hagedorn Research Institute,

Copenhagen, Denmark

T. Jørgensen $\cdot$ C. Pisinger

Research Centre for Prevention and Health,

Glostrup University Hospital,

Glostrup, Denmark

\section{T. Jørgensen}

Faculty of Health Sciences, University of Copenhagen,

Copenhagen, Denmark

D. R. Witte

Steno Diabetes Center,

Gentofte, Denmark

T. Hansen

Faculty of Health Sciences, University of Southern Denmark, Odense, Denmark

O. Pedersen

Institute of Biomedical Science, Faculty of Health Sciences, University of Copenhagen,

Copenhagen, Denmark

O. Pedersen

Faculty of Health Sciences, University of Aarhus,

Aarhus, Denmark 